\title{
Small hepatocyte-like progenitor cells may be a Hedgehog signaling pathway-controlled subgroup of liver stem cells
}

\author{
ZHIBIN WANG ${ }^{1 *}$, WEI LI ${ }^{2 *}, \mathrm{CHUN} \mathrm{LI}^{3}$, YANG YANG $^{3}$, WANG LI $^{4}$, LIYING ZHANG $^{5}$, \\ SHUMEI SUN ${ }^{5}$, JUNXIANG LI ${ }^{1}$ and YIDONG CAI ${ }^{5}$ \\ ${ }^{1}$ Department of Gastroenterology, Dongfang Hospital, Beijing University of Chinese Medicine, Beijing 100078; \\ ${ }^{2}$ Department of Gastroenterology, Beijing Friendship Hospital, Capital Medical University, Beijing 100050; \\ ${ }^{3}$ China Academy of Chinese Medical Sciences, Beijing 100700; ${ }^{4}$ Shanxi University of Traditional Chinese Medicine, \\ Taiyuan, Shanxi 030024; ${ }^{5}$ Department of Gastroenterology, Xiyuan Hospital, China Academy of Chinese Medical Sciences, \\ Beijing 100091, P.R. China
}

Received March 3, 2015; Accepted March 31, 2016

DOI: 10.3892/etm.2016.3675

\begin{abstract}
The present study aimed to investigate the expression levels of components of the Hedgehog signaling pathway (HH) during the proliferation of a liver stem cell subgroup, namely small hepatocyte-like progenitor cells (SHPCs). Retrorsine-treated Fisher 344 rats underwent a partial hepatectomy (PH) to induce the proliferation of SHPCs, after which reverse transcription-polymerase chain reaction (PCR), quantitative PCR, immunohistochemistry and western blot analysis were performed to analyze the expression of various components of the $\mathrm{HH}$ in primary SHPCs at different times points post-PH. A number of components of the $\mathrm{HH}$, including Indian hedgehog $(I H H)$, patched $(P T C H)$, smoothened and glioma-associated oncogene $(G L I) 1,2$ and 3, were continuously expressed and showed dynamic changes in proliferating SHPCs. In addition, the expression levels of $I H H, P T C H$ and GLII were significantly different as compared with those of the control group at the same time point, and there were significant differences among the various time points in the experimental group $(\mathrm{P}<0.01)$. Furthermore, there was an association between the postoperative day and expression levels of $\mathrm{HH}$ components in the retrorsine-treated group. An immunohistochemical analysis demonstrated that PTCH was
\end{abstract}

Correspondence to: Dr Yidong Cai, Department of Gastroenterology, Xiyuan Hospital, China Academy of Chinese Medical Sciences, 1 Xiyuan Cao Chang Road, Beijing 100091, P.R. China

E-mail: doctor_cyd@163.com

Professor Junxiang Li, Department of Gastroenterology, Dongfang Hospital, Beijing University of Chinese Medicine, 6, 1st Section, Fangxingyuan, Beijing 100078, P.R. China

E-mail: junxianglicn@126.com

*Contributed equally

Key words: Hedgehog signaling pathway, small hepatocyte-like progenitor cells, liver regeneration also expressed at the protein level. In conclusion, the results of the present study suggested that the $\mathrm{HH}$ was continuously activated during the proliferation of SHPCs, thus indicating that SHPCs may be a subgroup of stem cells that are regulated by the $\mathrm{HH}$.

\section{Introduction}

Retrorsine treatment combined with partial hepatecomy (PH) is a commonly used method to establish a model of liver regeneration (1). A subgroup of liver stem cells, termed small hepatocyte-like progenitor cells (SHPCs), has been previously shown to initiate liver regeneration in retrorsine-pretreated Fisher 344 rats that have undergone PH (2-3). The morphological characteristics and regeneration dynamics of SHPCs were found to be markedly different from the normal hepatic oval cells (1-3); however, the histological origin, cell biology characteristics and mechanisms that regulate the proliferation of SHPCs remain unclear.

In our previous study, it was demonstrated that the Hedgehog signaling pathway $(\mathrm{HH})$ was activated during various liver injury processes, including liver regeneration (4). The $\mathrm{HH}$ regulates the development of the embryonic digestive tract and its subsidiary organs, including the liver and pancreas $(5,6)$. The structures and functions of the various components of the $\mathrm{HH}$ have been reported in the literature $(5,6)$. Briefly, the signaling molecules Indian hedgehog (IHH) and sonic hedgehog (SHH) bind to the Patched (PTCH) membrane receptor, relieving inhibition of the transmembrane transduction protein Smoothened (SMO) $(5,6)$. This leads to the intracellular transduction of signals and eventual activation of the glioma-associated oncogene (GLI) family of zinc finger transcription factors, including $G L I 1, G L I 2$ and $G L I 3(5,6)$. This in turn results in the expression of GLI target genes, including PTCH, GLI and cyclin D, ultimately leading to changes in the cell cycle and cell proliferation and differentiation. At present, there is no consensus regarding the role of the $\mathrm{HH}$ in the mature liver and liver regeneration process (7-10). Furthermore, to the best of our knowledge, there have been no previous studies regarding the expression and significance 
of the $\mathrm{HH}$ in the SHPC-mediated regeneration process in the liver. Therefore, the present study aimed to investigate the expression levels of various components of the $\mathrm{HH}$, including $I H H, S H H, P T C H, S M O, G L I 1, G L I 2$ and GLI3, in primary SHPCs during liver regeneration, in order to elucidate the role of the HH in SHPC proliferation.

\section{Materials and methods}

Animals and liver regeneration model. A total of 140 male Fisher 344 rats (clean grade; average weight, 80 g; age, 5 weeks) were provided by the Shanghai Laboratory Animal Center of the Chinese Academy of Sciences (Shanghai, China). After 1 week of adaptive feeding, the rats were randomly divided into four groups, as follows (35 rats/group): i) Normal control (N) group; ii) retrorsine-treated (R) group; iii) $\mathrm{PH}$ group; and iv) $\mathrm{R}$ plus $\mathrm{PH}$ group (R/PH or SHPC group). Animals were maintained in conditions described in a previous study (4). The present study was conducted in accordance with recommendations in the Guide for the Care and Use of Laboratory Animals of the National Institutes of Health (Bethesda, MA, USA). The animal use protocol has been reviewed and approved by the Institutional Animal Care and Use Committee of the China Academy of Chinese Medical Sciences (Beijing, China). All experimental procedures were approved by Animal Ethics Committee of Beijing University of Chinese Medicine under the guidelines issued by Regulations of Beijing Laboratory Animal Management (Beijing, China).

In order to induce SHPC proliferation, the rats in the $\mathrm{R}$ and $\mathrm{R} / \mathrm{PH}$ groups were intraperitoneally injected with $30 \mathrm{mg} / \mathrm{kg}$ retrorsine (Sigma-Aldrich, St. Louis, MO, USA) once in week 6 and once in week 8 , as previously described $(1,2)$, The $\mathrm{N}$ and $\mathrm{PH}$ groups were injected with an equal volume of saline at these time points. At 5 weeks after the second dose (week 13), the $\mathrm{PH}$ and R/PH groups underwent a two-thirds PH (11), whereas the $\mathrm{N}$ and $\mathrm{R}$ groups underwent sham surgery to ensure that changes possibly caused by surgical trauma and narcotic drugs were accounted for in all groups (11). No mortalities caused by retrorsine administration and surgery occurred during the experiment. The rat-feeding and experiments were performed at the specific-pathogen-free Animal Experiment Center of the Dongfang Hospital (Beijing, China), and the surgical procedure was performed in accordance with the Regulations of Laboratory Animal Management (Beijing University of Chinese Medicine).

The rats from each group were sacrificed on days 2, 3, 4, 7, 14, 21 and 30 following $\mathrm{PH}$, with 5 rats from each group sacrificed at each time point, according to previous studies $(1,2)$. Following ligation and removal of the caudate lobe, the liver was separated in situ for preparation of primary SHPCs. The obtained caudate lobe was cut into 3-5 sections with a size of $0.5 \times 0.5 \times 0.2 \mathrm{~cm}$, fixed in $10 \%$ paraformaldehyde and embedded in paraffin $24 \mathrm{~h}$ later. Sections were then stained with hematoxylin and eosin and the proliferation of SHPCs were identified by three pathologists.

Separation and preparation of primary hepatocytes. The separation of hepatic tissues and the preparation of primary hepatocytes were performed according to previous reports $(12,13)$. Briefly, following ligation and resection of the caudate lobe, the in situ-isolated liver was perfused with $350 \mathrm{ml}$ EDTA solution at $37^{\circ} \mathrm{C}$ in Hanks' balanced salt solution (HBSS; Biyuntian Biological Technology Co., Ltd., Shanghai, China) via the abdominal aorta, at a flow rate of $35 \mathrm{ml} / \mathrm{min}$; the lavage solution was naturally discharged via the resected vena cava. Subsequently, $\mathrm{Ca}^{2+}$-enriched HBSS-dissolved $0.05 \%$ collagenase IV $\left(<38^{\circ} \mathrm{C}\right.$; Sigma-Aldrich), was perfused at the same rate for $10 \mathrm{~min}$. Upon separation of the liver capsule from the liver parenchyma, $150 \mathrm{ml}$ William's E medium $\left(4^{\circ} \mathrm{C}\right.$; Thermo Fisher Scientific, Inc., Waltham, MA, USA) was perfused at a flow rate of $150 \mathrm{ml} / \mathrm{min}$ for $1 \mathrm{~min}$. Next, the liver tissues were placed into a sterile mortar, chopped and homogenized, and then filtered using a stainless steel mesh (thickness, $150 \mu \mathrm{m}$; pore size, $80 \mu \mathrm{m}$ ) to eliminate the components of the liver parenchyma. The obtained filtrate was washed with $4^{\circ} \mathrm{C}$ William's E medium and centrifuged through a speed gradient to obtain the enriched primary hepatocytes or SHPCs. The centrifugation conditions were as follows, according to a previous study (13): Three times centrifugation $\left(4^{\circ} \mathrm{C}\right)$ at $50 \mathrm{x} \mathrm{g}$ for $1 \mathrm{~min}$ to obtain the enriched primary hepatocytes (as the control); subsequently, the lamellar sediment was discarded and the supernatant was centrifuged three times at $150 \mathrm{x} \mathrm{g}$ for 5 min to obtain the enriched primary SHPCs. The obtained primary SHPCs were placed into cell preservation solution (ABY; Aohua Medical Technology Co., Ltd., Xiaogan, China) for polymerase chain reaction (PCR) and western blotting, or placed into a low temperature refrigerator at $-80^{\circ} \mathrm{C}$ for future use.

Reverse transcription (RT)-PCR. RT-PCR was performed to detect the expression of molecular markers, including oval cell marker 6, cytokeratin 19 (CK19, hepatic duct system marker), CK18 (hepatocyte marker) and $\alpha$-smooth muscle actin (hepatic stellate cell marker), within the primary SHPCs at various time points following $\mathrm{PH}$. The primer sequences are shown in Tables I and II. PCR was performed using the CFX96 Touch real-time PCR system (Bio-Rad Laboratories, Inc., Hercules, CA, USA), according to the manufacturer's protocol. Briefly, total RNA was extracted from the primary SHPCs using TRIzol reagent (Invitrogen; Thermo Fisher Scientific, Inc.), followed by purification using DNase (Invitrogen; Thermo Fisher Scientific, Inc.). The purity was assessed by spectrophotometry. Total RNA (3 $\mu \mathrm{g}$ ) was added into $20 \mu \mathrm{l}$ PrimeScript RT kit (Takara Biotechnology Co., Ltd., Dalian, China) for reverse transcription into cDNA. cDNA (5 $\mu \mathrm{l})$ was then added into a $20 \mu \mathrm{l} \mathrm{PCR}$ reaction mixture, containing $4 \mu \mathrm{l}$ PrimeScript Buffer (5X), $1 \mu 1$ PrimeScript RT Enzyme Mix I, $1 \mu$ l Oligo Dt Primer (50 $\mu \mathrm{mol} / \mathrm{l})$, $1 \mu \mathrm{l}$ Random 6 mers $(100 \mu \mathrm{mol} / \mathrm{l})$ and $13 \mu \mathrm{l}$ total RNA. The PCR system (15 $\mu$ l for each sample) was as follows: $7.5 \mu 1$ Premix Ex Taq (2X), $0.25 \mu \mathrm{l}$ forward primer (10 $\mu \mathrm{mol} / \mathrm{l}), 0.25 \mu \mathrm{l}$ reverse

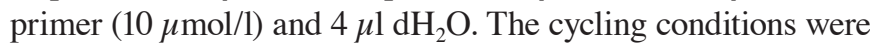
as follows: $93^{\circ} \mathrm{C}$ for $5 \mathrm{~min}$, followed by 35 cycles of $94^{\circ} \mathrm{C}$ for $30 \mathrm{sec}, 54^{\circ} \mathrm{C}$ for $45 \mathrm{sec}$ and $72^{\circ} \mathrm{C}$ for $1 \mathrm{~min}$, and a final extension step at $72^{\circ} \mathrm{C}$ for $10 \mathrm{~min}$. The reaction products were subjected to $2 \%$ agarose gel electrophoresis. Ethidium bromide was used to visualize the DNA ladder. The remaining cDNA was stored at $-20^{\circ} \mathrm{C}$ until further use.

Quantitative PCR ( $q$ PCR). A semi-quantitative fluorescence probe method was used to analyze the expression levels of 
Table I. Primer sequences for reverse transcription-polymerase chain reaction.

\begin{tabular}{|c|c|c|}
\hline Gene & Primers & Product size (bp) \\
\hline$C D 45$ & $\begin{array}{l}\text { F: 5'-TGTCGTGACGATCAATGACCA-3' } \\
\text { R: 5'-ACATCCACTTTGCCCTCTGCT-3' }\end{array}$ & 306 \\
\hline$C D 133$ & $\begin{array}{l}\text { F: 5'-ACCAGTTGCCTGACGGAAATC-3' } \\
\text { R: 5'-GCGTACAAGACCCATTGCAGAT-3' }\end{array}$ & 304 \\
\hline$C D 117$ & $\begin{array}{l}\text { F: 5'-GGCATCACCATCAAAAACGTG-3' } \\
\text { R: 5'-TGGCGTTCGTAATTGAAGTCG-3' }\end{array}$ & 317 \\
\hline CD326 & $\begin{array}{l}\text { F: 5'-GATGAAGGCGGAGATGACTCAC-3' } \\
\text { R: 5'-CGAGATGCAAATGTGTCCTGAA-3' }\end{array}$ & 315 \\
\hline CK18 & $\begin{array}{l}\text { F: 5'-GGATGCTCCCAAATCTCAGGA-3' } \\
\text { R: 5'-TGATTCCAGATGCAGAAGGACC-3' }\end{array}$ & 331 \\
\hline CK19 & $\begin{array}{l}\text { F: 5'-TCCACACCAGGCATTGACCTA-3' } \\
\text { R: 5'-GCCTCGACTTGATGTCCATGA-3' }\end{array}$ & 403 \\
\hline$C L D N 3$ & $\begin{array}{l}\text { F: 5'-CGAGCTCTCATCGTGGTGTCTA-3' } \\
\text { R: 5'-CGTACAACCCAGTTCCCATCTC-3' }\end{array}$ & 256 \\
\hline$c-M e t$ & $\begin{array}{l}\text { F: 5'-TCAACAGCGGCAATTCTAGACA-3' } \\
\text { R: 5'-GTGGTGCAGCAGATGATCTCTG-3' }\end{array}$ & 364 \\
\hline$C \times 43$ & $\begin{array}{l}\text { F: 5'-TTCATGCTGGTGGTGTCCTTG-3' } \\
\text { R: 5'-CGATTTTGCTCTGCGCTGTAGT-3' }\end{array}$ & 323 \\
\hline$H N F 3 \beta$ & $\begin{array}{l}\text { F: 5'-CCAACAAGATGCTGACGCTGA-3' } \\
\text { R: 5'-TGAACCTGAGAAGCCTGTGTCC-3' }\end{array}$ & 331 \\
\hline$H N F 4 \alpha$ & $\begin{array}{l}\text { F: 5'-AGGCAGTGCGTGGTAGACAAA-3' } \\
\text { R: 5'-TGAACACCATGGACCTCTTGG-3' }\end{array}$ & 421 \\
\hline$O V-6$ & $\begin{array}{l}\text { F: 5'-ATGACATGAAGGTTGTCCTCGG-3' } \\
\text { R: 5'-CCCCTTGGTCTTAACATGCTGA-3' }\end{array}$ & 263 \\
\hline Sca-1 & $\begin{array}{l}\text { F: 5'-GCACGATGATCCCATTTGGT-3' } \\
\text { R: 5'-TGCTGCGTTGCAAAGATCTG-3' }\end{array}$ & 230 \\
\hline Thyl & $\begin{array}{l}\text { F: 5'-TGCCGTCATGAGAATAACACCA-3' } \\
\text { R: 5'-ACACATGTAGTCGCCCTCATCC-3' }\end{array}$ & 201 \\
\hline $\mathrm{SHH}$ & $\begin{array}{l}\text { F: 5'-AACTCACCCCCAATTACAACCC-3' } \\
\text { R: 5'-GGATGCGAGCTTTGGATTCA-3' }\end{array}$ & 321 \\
\hline$I H H$ & $\begin{array}{l}\text { F: 5'-ACCGCGACCGAAATAAGTACG-3' } \\
\text { R: 5'-AAAGCTCTCAGCCTGTTTGGC-3' }\end{array}$ & 301 \\
\hline РTCH & $\begin{array}{l}\text { F: 5'-TGTTGGTGTGGACGACGTCTT-3' } \\
\text { R: 5'-GGTTCAACTTGAATCACCCGG-3' }\end{array}$ & 354 \\
\hline$V I M$ & $\begin{array}{l}\text { F: 5'-TACATCGACAAGGTGCGCTTC-3' } \\
\text { R: 5'-TCGATCTGGACATGCTGTTCC-3' }\end{array}$ & 422 \\
\hline$\alpha-S M A$ & $\begin{array}{l}\text { F: 5'-TGGAGAAGAGCTACGAACTGCC-3' } \\
\text { R: 5'-ATAGAGAAGCCAGGATGGAGCC-3' }\end{array}$ & 342 \\
\hline
\end{tabular}

F, forward; R, reverse; $C K$, cytokeratin; $C L D N 3$, claudin-3; $C x 43$, connexin 43; $H N F$, hepatocyte nuclear factor; $O V$-6, oval cell marker 6; Sca-1, stem cell antigen 1; Thyl, thymocyte antigen 1; SHH, sonic hedgehog; IHH, Indian hedgehog; PTCH, patched; VIM, vimentin; $\alpha$-SMA, $\alpha$-smooth muscle actin.

$I H H, P T C H$ and GLII within the primary cell extract of each group at various time points. The primers and fluorescent probe sequences are shown in Table III. PCR was performed on the stored cDNA using the PE 7000 automated fluorescence qPCR instrument (Perkin Elmer Corp., Waltham, MA, USA), according to the manufacturer's protocol. Briefly, $5 \mathrm{ml} \mathrm{cDNA}$, primers and probes were added to the PCR reaction solution (7.5 $\mu$ l Premix Ex Taq (2X) and $4 \mu \mathrm{l} \mathrm{dH}_{2} \mathrm{O}$ ) and the cycling conditions were as follows: 40 Cycles of $93^{\circ} \mathrm{C}$ for $3 \mathrm{~min}, 93^{\circ} \mathrm{C}$ for $45 \mathrm{sec}$ and $55^{\circ} \mathrm{C}$ for $1 \mathrm{~min}$. Following the reaction, the computer automatically analyzed the results. GAPDH was used as the internal control. The relative mRNA expression levels were calculated using the $2^{-\Delta \Delta \mathrm{Cq}}$ method (14). Each reaction was repeated three times, and the final result for a specific time point is presented as the mean of these three measurements.

Immunohistochemical and western blot analyses. Immunohistochemical and western blot analyses were performed to detect the protein expression of IHH, PTCH and GLI1 
Table II. Reverse transcription-polymerase chain reaction primer sequences for components of the Hedgehog signaling pathway.

\begin{tabular}{|c|c|c|}
\hline Gene & Primers & Product size (bp) \\
\hline $\mathrm{SHH}$ & $\begin{array}{l}\text { F: 5'-AACTCACCCCCAATTACAACCC-3' } \\
\text { R: 5'-GGATGCGAGCTTTGGATTCA-3' }\end{array}$ & 321 \\
\hline$I H H$ & $\begin{array}{l}\text { F: 5'-ACCGCGACCGAAATAAGTACG-3' } \\
\text { R: 5'-AAAGCTCTCAGCCTGTTTGGC-3' }\end{array}$ & 301 \\
\hline PTCH & $\begin{array}{l}\text { F: 5'-TGTTGGTGTGGACGACGTCTT-3' } \\
\text { R: 5'-GGTTCAACTTGAATCACCCGG-3' }\end{array}$ & 354 \\
\hline$S M O$ & $\begin{array}{l}\text { F: 5'-CAATGTGAAGCACCCTTGGTG-3' } \\
\text { R: 5'-CCATCTGCTCGGCAAACAAT-3' }\end{array}$ & 323 \\
\hline GLII & $\begin{array}{l}\text { F: 5'-CCAGTGTCCTCGACTTGAGCAT-3' } \\
\text { R: 5'-ACAATTCCTGCTGCGACTGAAC-3' }\end{array}$ & 323 \\
\hline$G L I 2$ & $\begin{array}{l}\text { F: 5'-TGGATCTCTGAACCAGTTTGCC-3' } \\
\text { R: 5'-TCGGTGACGACTAGCTGTGTTG-3' }\end{array}$ & 325 \\
\hline GLI3 & $\begin{array}{l}\text { F: 5'-ATCAAAATGGAGGCACACGG-3' } \\
\text { R: 5'-CCCTGACATTAGGCTGGTATGG-3' }\end{array}$ & 303 \\
\hline
\end{tabular}

SHH, sonic hedgehog; IHH, Indian hedgehog; PTCH, patched; SMO, smoothened; GLI, glioma-associated oncogene; F, forward; R, reverse.

Table III. Sequences of the primers and probes used for quantitative polymerase chain reaction.

\begin{tabular}{|c|c|c|}
\hline Gene & Primers and probes & Product size (bp) \\
\hline$I H H$ & $\begin{array}{l}\text { F: 5'-CGGCCATCACTCAGAGGAAT-3' } \\
\text { R: 5'-CTGCTAAGCGCGCCAGTAGT-3' } \\
\text { P: 5'-FAM-TTTACACTATGAGGGCCGCGC-TAMRA-3' }\end{array}$ & 104 \\
\hline PTCH & $\begin{array}{l}\text { F: 5'-GCCTTTCTGACAGCCATTGG-3' } \\
\text { R: 5'-CACCCAGCAGAGTGGACACA-3' } \\
\text { P: 5'-FAM-CAAGAACCACAGGGCTATGCTCGC-TAMRA-3' }\end{array}$ & 103 \\
\hline GLII & $\begin{array}{l}\text { F: 5'-CCTGAAGTGGGCAGGTTAGG-3' } \\
\text { R: 5'-GCTGAGTGTTGTCCAGGTCAAG-3' } \\
\text { P: 5'-FAM-AGGGCAGGTGTGTAACCCTCTGG-TAMRA-3' }\end{array}$ & 100 \\
\hline
\end{tabular}

IHH, Indian hedgehog; PTCH, patched; GLI1, glioma-associated oncogene 1; F, forward; R, reverse; P, probe.

within the liver tissue sections, according to previous studies $(4,8,9,15)$. The following antibodies were purchased from Santa Cruz Biotechnology Inc. (Dallas, TX, USA) and used in the present study: Goat anti-IHH (C-15; immunohistochemistry) and anti-IHH (I-19; western blot) polyclonal antibodies (cat. nos. sc-1196 and sc-1782, respectively; 1:50); rabbit anti-PTCH polyclonal antibody (H-267; sc-9016; 1:50); goat anti-GLI1 polyclonal antibody (N-16; sc-6153; 1:50); and horseradish peroxidase-conjugated rabbit anti-goat (sc-2033; $1: 1,000)$ and goat anti-rabbit (sc-2004; 1:1,000) polyclonal secondary antibodies. A negative control consisted of $0.01 \mathrm{~mol} / \mathrm{l}$ phosphate-buffered saline instead of the primary antibody.

Statistical analysis. Data are presented as the mean \pm standard deviation. Repeated measures analysis of variance was used to compare the expression levels of IHH, PTCH and GLI1 between the experimental and control groups at various time points. Statistical analyses were conducted with SPSS 13.0 software (SPSS, Inc., Chicago, IL, USA).
$\mathrm{P}<0.05$ was considered to indicate a statistically significant difference.

\section{Results}

Expression of HH components and other molecular markers. RT-PCR demonstrated that $\mathrm{IHH}$ and $\mathrm{PTCH}$ were continuously expressed in the early, middle and late stages of SHPC proliferation (postoperative days 4, 14 and 30, respectively), whereas SHH mRNA expression was negative. In addition, a number of other molecular markers were expressed in the primary SHPC extract, including oval cell marker 6, CK19, CK18 and $\alpha$-smooth muscle actin. These results suggested there were a variety of cell components in the extract (Fig. 1), in agreement with previous findings (16-20).

According to Gordon et al $(1,2)$, SHPC regeneration presented a diffused distribution and continued proliferation. In the present study, RT-PCR detected the continuous expression of $\mathrm{HH}$-associated genes on postoperative days 2, 3, 4, 7, 14, 21 and 30. IHH, PTCH, GLII, GLI2 and GLI3 mRNA 

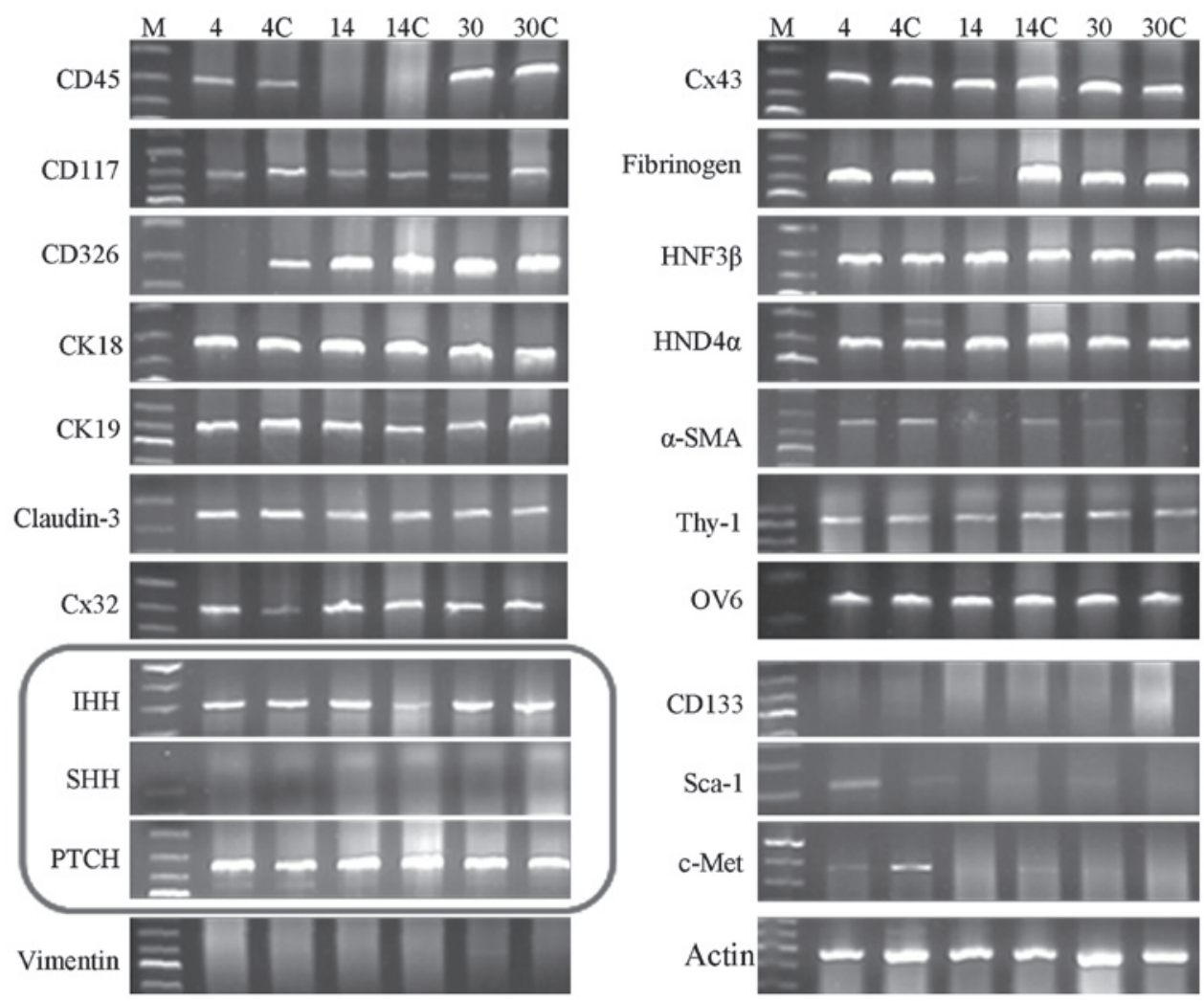

Figure 1. Expression of various molecular markers in the cell homogenate of primary SHPCs. Reverse transcription-polymerase chain reaction demonstrated that numerous molecular markers were expressed in primary SHPCs undergoing proliferation in the early, middle and late stages of liver regeneration (postoperative days 4,14 and 30, respectively). Primary SHPCs from the retrorsine-treated group within the same period (postoperative days 4, 14 and 30 ) were set as the controls (4C, $14 \mathrm{C}$ and $30 \mathrm{C}$, respectively). The circled pane shows that $I H H$ and $P T C H$ were continuously expressed, whereas $S H H$ was not. SHPCs, small hepatocyte-like progenitor cells; $I H H$, Indian hedgehog; $P T C H$, patched; $S H H$, sonic hedgehog.

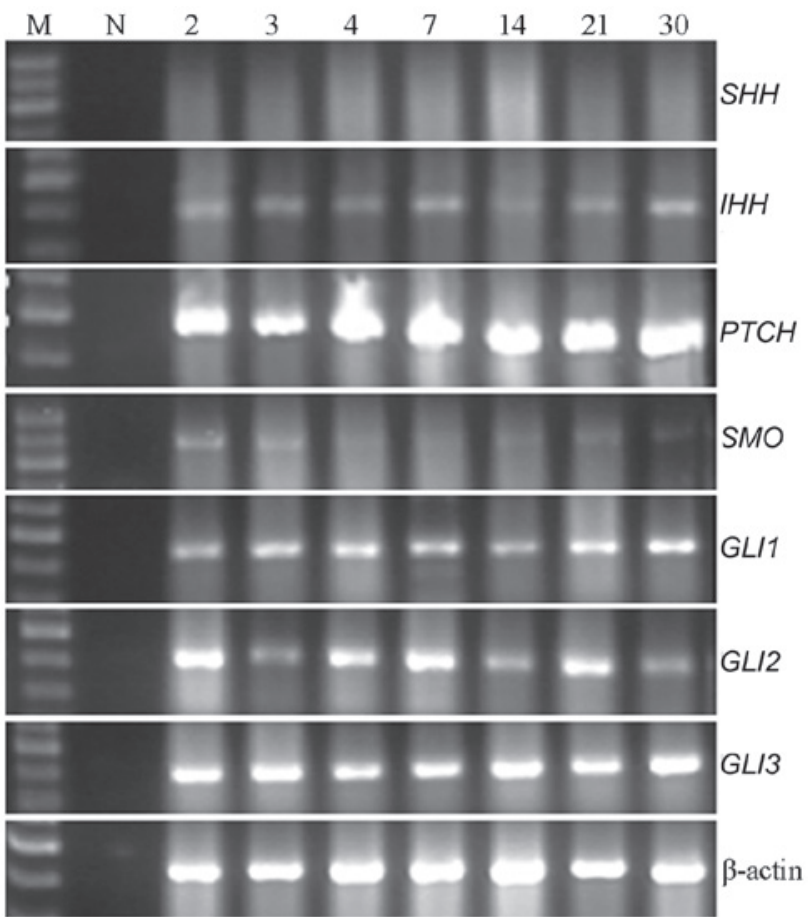

Figure 2. Expression levels of various Hedgehog signaling pathway components in proliferating SHPCs. On postoperative days 2, 3, 4, 7, 14, 21 and 30, $I H H, P T C H, G L I 1, G L I 2$ and GLI were continuously expressed in the cell homogenate of primary SHPCs, whereas $S M O$ was only weakly expressed and $S H H$ expression was negligible. SHPCs, small hepatocyte-like progenitor cells M, DNA marker; N, negative control; $S H H$, sonic hedgehog; $P T C H$, patched $I H H$, Indian hedgehog; SMO, smoothened; $G L I$, glioma-associated oncogene. expression was consistently observed in the primary SHPCs, whereas $S M O$ was expressed at a low level (Fig. 2) and the expression of $\mathrm{SHH}$ was negligible. These results confirm the continued activation of $\mathrm{HH}$ in the process of proliferation of SHPCs.

Activation status of the HH during the proliferation of SHPCs. In order to further clarify the role of $\mathrm{HH}$ activation in the process of liver regeneration, qPCR was performed to detect the expression levels of $I H H, P T C H$ and GLII in the SHPC extract at various time points. IHH is a signaling molecule that is synthesized and released into the microenvironment. The synthesis of GLI1 is entirely dependent on the stimulation of the $\mathrm{HH}$, such that GLI1 is considered a direct marker of $\mathrm{HH}$ activation $(8,21,22)$. In addition, $\mathrm{PTCH}$ is not only a membrane receptor for the $\mathrm{HH}$, but also a target protein of $\mathrm{HH}$ activation, which may establish a negative feedback mechanism that helps to avoid the abnormal or excessive activation of $\mathrm{HH}(8,21)$. Therefore, upregulation of PTCH expression has been regarded as a sign of the constitutive activation of the $\mathrm{HH}(8,21)$.

In the present study, the expression levels of $\mathrm{IHH}, \mathrm{PTCH}$ and GLII were significantly different in proliferating SHPCs, as compared with the control group at the same time points, as well as among the different time points within the R/PH group $(\mathrm{P}<0.01)$. Furthermore, there was an association between the postoperative time point and the expression levels of the $\mathrm{HH}$ components in the R/PH group. However, the same 
Table IV. Expression of Indian hedgehog during the regeneration of small hepatocyte-like progenitor cells.

\begin{tabular}{|c|c|c|c|c|c|c|}
\hline Time $^{\mathrm{a}}$ & $\mathrm{n}$ & $\mathrm{N}$ & $\mathrm{R}$ & $\mathrm{PH}$ & $\mathrm{R} / \mathrm{PH}$ & P-value \\
\hline 2 & 5 & $0.461 \pm 0.014$ & $0.544 \pm 0.032$ & $0.765 \pm 0.009$ & $0.651 \pm 0.022$ & 0.014 \\
\hline 3 & 5 & $0.463 \pm 0.005$ & $0.546 \pm 0.016$ & $0.610 \pm 0.100$ & $0.987 \pm 0.100$ & $<0.001$ \\
\hline 4 & 5 & $0.456 \pm 0.020$ & $0.552 \pm 0.025$ & $0.523 \pm 0.010$ & $0.554 \pm 0.070$ & 0.060 \\
\hline 7 & 5 & $0.493 \pm 0.015$ & $0.560 \pm 0.013$ & $0.300 \pm 0.047$ & $0.543 \pm 0.010$ & 0.020 \\
\hline 14 & 5 & $0.556 \pm 0.009$ & $0.539 \pm 0.060$ & $0.443 \pm 0.013$ & $0.534 \pm 0.080$ & 0.041 \\
\hline 21 & 5 & $0.562 \pm 0.030$ & $0.566 \pm 0.010$ & $0.553 \pm 0.050$ & $0.507 \pm 0.010$ & 0.120 \\
\hline 30 & 5 & $0.555 \pm 0.060$ & $0.560 \pm 0.015$ & $0.672 \pm 0.020$ & $0.536 \pm 0.030$ & 0.016 \\
\hline P-value & & 0.54 & 0.39 & 0.002 & $<0.001$ & \\
\hline
\end{tabular}

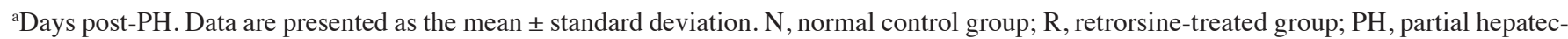
tomy; R/PH, retrorsine-treated plus PH group.

Table V. Expression of glioma-associated oncogene 1 during the regeneration of small hepatocyte-like progenitor cells.

\begin{tabular}{|c|c|c|c|c|c|c|}
\hline Time $^{\mathrm{a}}$ & $\mathrm{n}$ & $\mathrm{N}$ & $\mathrm{R}$ & PH & $\mathrm{R} / \mathrm{PH}$ & $\mathrm{P}$-value \\
\hline 2 & 5 & $0.261 \pm 0.014$ & $0.280 \pm 0.007$ & $0.566 \pm 0.001$ & $0.651 \pm 0.022$ & 0.021 \\
\hline 3 & 5 & $0.263 \pm 0.005$ & $0.277 \pm 0.004$ & $0.610 \pm 0.100$ & $0.780 \pm 0.100$ & 0.034 \\
\hline 4 & 5 & $0.255 \pm 0.090$ & $0.290 \pm 0.005$ & $0.523 \pm 0.010$ & $0.354 \pm 0.040$ & 0.027 \\
\hline 7 & 5 & $0.262 \pm 0.015$ & $0.287 \pm 0.030$ & $0.270 \pm 0.047$ & $0.343 \pm 0.010$ & 0.004 \\
\hline 14 & 5 & $0.256 \pm 0.020$ & $0.274 \pm 0.014$ & $0.241 \pm 0.013$ & $0.311 \pm 0.005$ & 0.017 \\
\hline 21 & 5 & $0.261 \pm 0.030$ & $0.277 \pm 0.010$ & $0.154 \pm 0.050$ & $0.287 \pm 0.010$ & $<0.001$ \\
\hline 30 & 5 & $0.255 \pm 0.060$ & $0.280 \pm 0.040$ & $0.172 \pm 0.020$ & $0.290 \pm 0.030$ & $<0.001$ \\
\hline P-value & & 0.245 & 0.43 & $<0.01$ & $<0.01$ & \\
\hline
\end{tabular}

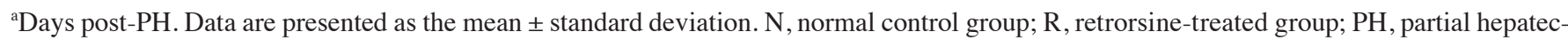
tomy; R/PH, retrorsine-treated plus PH group.

Table VI. Expression of patched during the regeneration of small hepatocyte-like progenitor cells.

\begin{tabular}{|c|c|c|c|c|c|c|}
\hline Time $^{\mathrm{a}}$ & $\mathrm{n}$ & $\mathrm{N}$ & $\mathrm{R}$ & PH & $\mathrm{R} / \mathrm{PH}$ & P-value \\
\hline 2 & 5 & $0.161 \pm 0.014$ & $0.185 \pm 0.060$ & $0.166 \pm 0.080$ & $0.150 \pm 0.022$ & 0.032 \\
\hline 3 & 5 & $0.164 \pm 0.004$ & $0.178 \pm 0.090$ & $0.219 \pm 0.040$ & $0.186 \pm 0.110$ & 0.019 \\
\hline 4 & 5 & $0.155 \pm 0.090$ & $0.193 \pm 0.040$ & $0.323 \pm 0.010$ & $0.254 \pm 0.040$ & 0.006 \\
\hline 7 & 5 & $0.182 \pm 0.012$ & $0.189 \pm 0.030$ & $0.290 \pm 0.037$ & $0.343 \pm 0.010$ & $<0.001$ \\
\hline 14 & 5 & $0.156 \pm 0.010$ & $0.168 \pm 0.015$ & $0.241 \pm 0.020$ & $0.534 \pm 0.050$ & $<0.001$ \\
\hline 21 & 5 & $0.161 \pm 0.030$ & $0.175 \pm 0.011$ & $0.154 \pm 0.045$ & $0.507 \pm 0.010$ & $<0.001$ \\
\hline 30 & 5 & $0.155 \pm 0.060$ & $0.180 \pm 0.020$ & $0.152 \pm 0.020$ & $0.536 \pm 0.028$ & $<0.001$ \\
\hline P-value & & 0.48 & 0.52 & $<0.001$ & $<0.001$ & \\
\hline
\end{tabular}

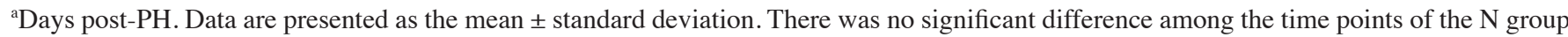
$(\mathrm{P}>0.05)$. N, normal control group; R, retrorsine-treated group; $\mathrm{PH}$, partial hepatectomy; R/PH, retrorsine-treated plus $\mathrm{PH}$ group.

association was not observed for the $\mathrm{N}$ and $\mathrm{R}$ groups $(\mathrm{P}>0.05$; Tables IV-VI). In contrast to the expression in the N, R and PH groups, significantly higher expression levels of IHH and GLII were observed during the early stage of SHPC proliferation in the R/PH group (the earliest detection point in this experiment was day 2 post-PH). Conversely, the expression levels of $I H H$ and GLII gradually decreased after reaching a peak on day 3 post-PH. Subsequently, $I H H$ and GLII expression levels approached similar levels as in the control group on days 4-7 post-PH, although the difference between the control and $\mathrm{R} / \mathrm{PH}$ groups remained significant $(\mathrm{P}<0.05)$, with the exception of IHH expression on the days 4 and 21 post-PH (Tables IV-VI). The expression of $P T C H$ exhibited the opposite pattern, since it was lower compared with that in the $\mathrm{N}$ group at the early 

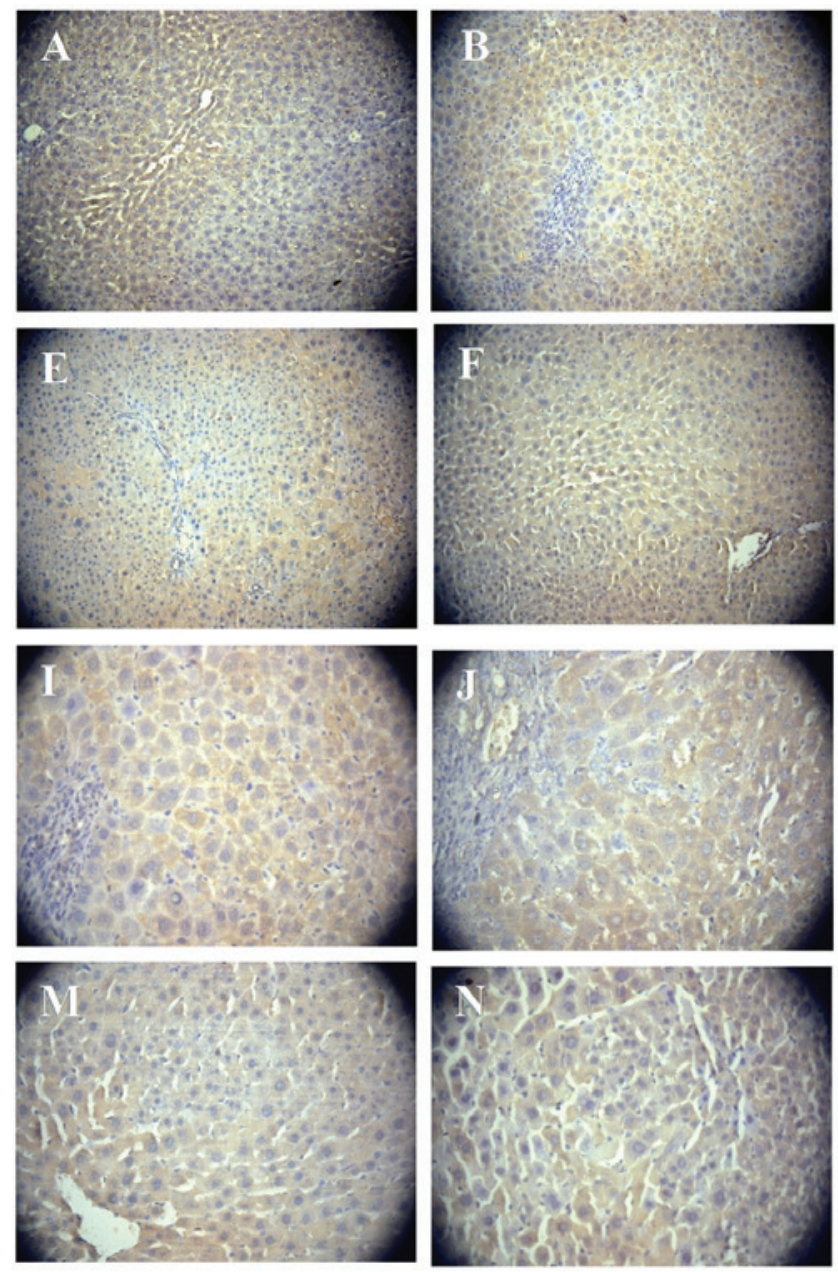
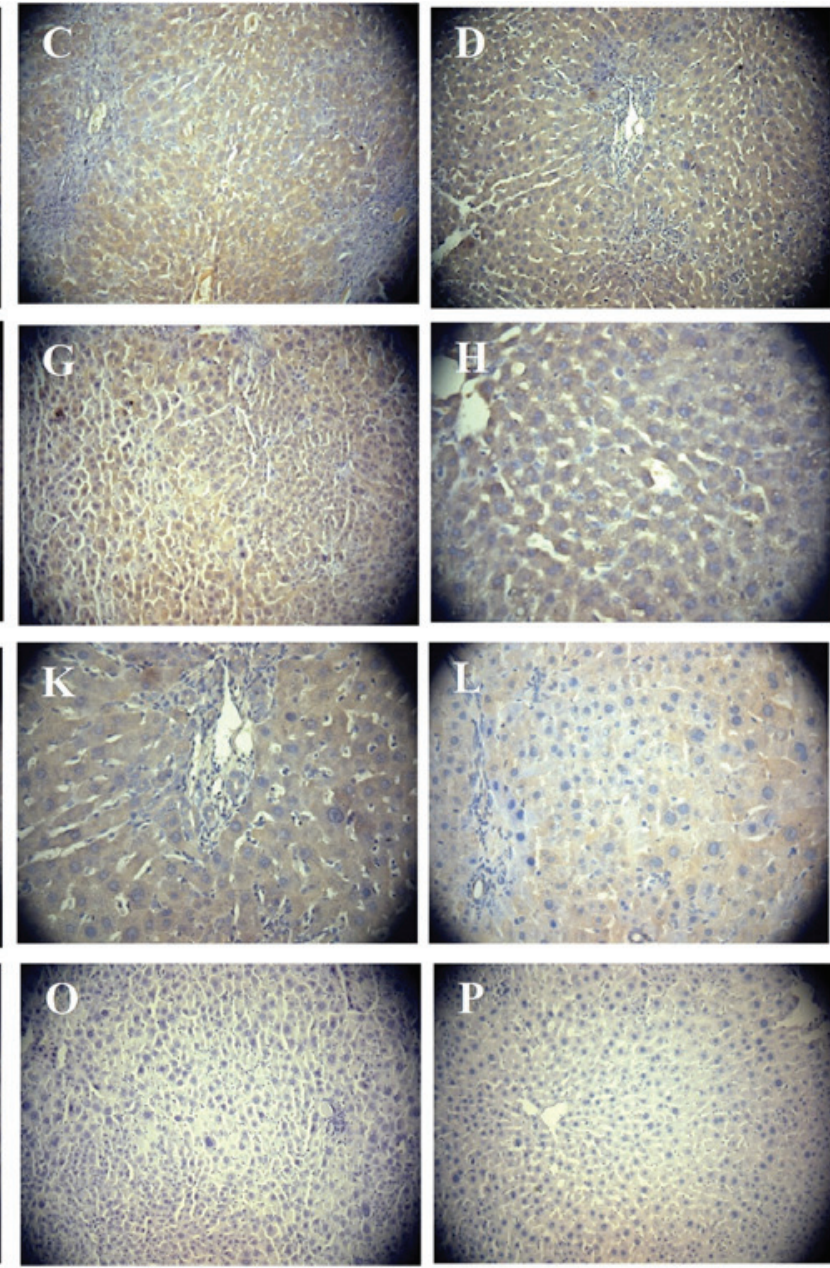

Figure 3. Immunohistochemical detection of PTCH and IHH in proliferating SHPCs. Immunohistochemistry detected the expression levels of PTCH and IHH in regenerated liver tissues during SHPC proliferation. (A)-(G), magnification x200; (H)-(N), magnification x400; (O) and (P), magnification x200. PTCH was continuously strongly expressed on postoperative days (A and H) 2, (B and I) 3, (C and J) 4, (D and K) 7, (E and L) 14, (F and M) 21 and (G and N) 30, as demonstrated by cells with large brown membranes or cytoplasmic staining, diffused inside the liver parenchyma. (O) Negative control without the anti-PTCH antibody. (P) Regenerated liver tissue sections showed no IHH expression. PTCH, patched; IHH, Indian hedgehog; SHPC, small hepatocyte-like progenitor cells.

stages, but gradually increased and reached a peak on day 14 post-PH. In addition, the expression levels of $P T C H$ remained elevated until day 30 post-PH.

Expression of HH components at the protein level. The protein expression levels of IHH, PTCH and GLI1 were detected by immunohistochemical and western blot analyses. In proliferating SHPCs, PTCH was constitutively expressed at a high level and, in the post-PH day 30 liver tissue sections, a large number of cells with brown membranes and a stained cytoplasm were diffused within the liver parenchyma (Fig. 3). By contrast, the expression of IHH was negative (Fig. 3) and GLI1 exhibited weak non-specific staining, and was thus difficult to confirm its expression (data not shown). Western blot analysis was unable to detect the expression of the three indicators.

\section{Discussion}

Retrorsine-treated Fisher 344 rats may be able to complete the compensation of hepatic structural defects and functional loss by SHPCs in one time- and space-specific way after PH (1-3). Previous studies have demonstrated that SHPCs are a group of non-oval, non-bile duct cells that may be a stem cell subgroup derived from mature hepatocytes (23-25). However, the following features of SHPCs have yet to be fully elucidated: i) The histological origin and anatomical location of SHPCs; ii) the characteristic cytobiological features of SHPCs, in particular specific molecular markers and gene/protein expression profiles; iii) the mechanisms and signaling pathways underlying the regulation of SHPC proliferation; and iv) evidence that SHPCs exist in other mammalian species.

In previous studies, SHPC regeneration presented a diffused distribution and continued proliferation $(1,2)$. Therefore, the present study aimed to identify the signaling pathways involved in SHPC proliferation. RT-PCR demonstrated that numerous components of the $\mathrm{HH}$ were continuously expressed in primary SHPCs undergoing proliferation, and a quantitative analysis suggested that alterations in the expression levels of $I H H$, $P T C H$ and $G L I I$ were indicative of $\mathrm{HH}$ activation. These results suggested that, during the process of SHPC proliferation, IHH is secreted and binds to the membrane receptor $\mathrm{PTCH}$ in order to reduce the expression of $\mathrm{PTCH}$, and relieve the inhibition of the $\mathrm{HH}$, thus upregulating the expression of the GLII target gene. However, following sustained activation of the pathway, 
the expression of PTCH was increased and ultimately sustained at a high level, thereby providing a negative feedback mechanism that inhibited excessive activation of the HH. This was accompanied by a gradual decrease in the expression levels of $I H H$ and $G L I l$, reflecting the continuous activation of $\mathrm{HH}$ and the $P T C H$-mediated negative feedback mechanism $(5,6)$. Notably, the results of the present study were consistent with those of Ochoa et al (10) and Agarwal et al (26), who also analyzed the expression of PTCH, SMO, GLII, GLI2 and GLI3 in liver tissues. However, in contrast to these experiments, the present study was able to detect the expression of $I H H$, but not $S H H$, in the experimental and control groups. These results suggested that, in proliferating SHPCs, the HH may exert its physiological role via IHH rather than SHH, although these discrepancies may be associated with differences in the modeling method or differences in the genus/species used, and thus further verification is required.

The present study used immunohistochemistry to analyze the expression of $\mathrm{HH}$ components at the protein level and demonstrated that PTCH was continuously expressed in proliferating SHPCs. By contrast, western blot analysis was unable to further validate the results of the immunohistochemical analysis, which may have been due to a lack of reliable antibodies for detection of the mammalian liver $\mathrm{HH}$ molecules $(4,9,10,15)$. Another reason for the unsuccessful detection may have been that, during the activation of the $\mathrm{HH}$, the binding of the IHH signaling molecule to the PTCH membrane receptor may have altered the structure and location of the proteins, which in turn may have affected their extraction, identification and reaction with the antibodies $(5,6,21)$.

In conclusion, to the best of our knowledge, the present study is the first to report the constitutive activation of a signaling pathway, in particular the $\mathrm{HH}$, in proliferating SHPCs. The results of the present study suggested that the $\mathrm{HH}$ may serve an important role in the proliferation of SHPCs, and that SHPCs may be an HH-regulated stem cell subgroup. Further studies are required to validate these results, elucidate the histological position of SHPCs within the liver and observe the impacts of pathway blockage on SHPC proliferation, in order to delineate the regulatory mechanisms underlying SHPC proliferation and identify the role of the HH in liver regeneration.

\section{References}

1. Gordon GJ, Coleman WB, Hixson DC and Grisham JW: Liver regeneration in rats with retrorsine-induced hepatocellular injury proceeds through a novel cellular response. Am J Pathol 156: 607-619, 2000.

2. Gordon GJ, Coleman WB and Grisham JW: Temporal analysis of hepatocyte differentiation by small hepatocyte-like progenitor cells during liver regeneration in retrorsine-exposed rats. Am J Pathol 157: 771-786, 2000.

3. Hunter Best D and Coleman WB: Cells of origin of small hepatocyte-like progenitor cells in the retrorsine model of rat liver injury and regeneration. J Hepatol 48: 369-371, 2008.

4. Cai Y, Zheng H, Gong W, Che Y and Jiang B: The role of hedgehog signaling pathway in liver regeneration. Hepatogastroenterology 58: 2071-2076, 2011.

5. Petrova R and Joyner AL: Roles for Hedgehog signaling in adult organ homeostasis and repair. Development 141: 3445-3457, 2014.
6. Merchant JL: Hedgehog signalling in gut development, physiology and cancer. J Physiol 590: 421-432, 2012.

7. McMillan R and Matsui W: Molecular pathways: The hedgehog signaling pathway in cancer. Clin Cancer Res 18: 4883-4888, 2012.

8. Büller NV, Rosekrans SL, Westerlund J and van den Brink GR: Hedgehog signaling and maintenance of homeostasis in the intestinal epithelium. Physiology (Bethesda) 27: 148-155, 2012.

9. Tang L, Tan YX, Jiang BG, Pan YF, Li SX, Yang GZ, Wang M, Wang Q, Zhang J, Zhou WP, et al: The prognostic significance and therapeutic potential of hedgehog signaling in intrahepatic cholangiocellular carcinoma. Clin Cancer Res 19: 2014-2024, 2013.

10. Ochoa B, Syn WK, Delgado I, Karaca GF, Jung Y, Wang J, Zubiaga AM, Fresnedo O, Omenetti A, Zdanowicz M, et al: Hedgehog signaling is critical for normal liver regeneration after partial hepatectomy in mice. Hepatology 51: 1712-1723, 2010.

11. Palmes D and Spiegel HU: Animal models of liver regeneration. Biomaterials 25: 1601-1611, 2004.

12. Papeleu P, Vanhaecke T, Henkens T, Elaut G, Vinken M, Snykers S and Rogiers V: Isolation of rat hepatocytes. Methods Mol Biol 320: 229-237, 2006.

13. Gordon GJ, Butz GM, Grisham JW and Coleman WB: Isolation, short-term culture and transplantation of small hepatocyte-like progenitor cells from retrorsine-exposed rats. Transplantation 73: 1236-1243, 2002.

14. Livak KJ and Schmittgen TD: Analysis of relative gene expression data using real-time quantitative PCR and the 2(-Delta Delta C(T)) Method. Methods 25: 402-408, 2001.

15. Furmanski AL, Saldana JI, Ono M, Sahni H, Paschalidis N, D'Acquisto $\mathrm{F}$ and Crompton T: Tissue-derived hedgehog proteins modulate the differentiation and disease. J Immunol 190: 2641-2649, 2013

16. Than NN and Newsome PN: Stem cells for liver regeneration. QJM 107: 417-421, 2014.

17. Snykers S, De Kock J, Vanhaecke T and Rogiers V: Differentiation of neonatal rat epithelial cells from biliary origin into immature hepatic cells by sequential exposure to hepatogenic cytokines and growth factors reflecting liver development. Toxicol In Vitro 21: 1325-1331, 2007.

18. Tanaka M, Itoh $\mathrm{T}$, Tanimizu $\mathrm{N}$ and Miyajima A: Liver stem/progenitor cells: Their characteristics and regulatory mechanisms. J Biochem 149: 231-239, 2011.

19. Koenig S, Krause P, Drabent B, Schaeffner I, Christ B, Schwartz P, Unthan-Fechner K and Probst I: The expression of mesenchymal, neural and haematopoietic stem cell markers in adult hepatocytes proliferating in vitro. J Hepatol 44: 1115-1124, 2006.

20. Böhm F, Köhler UA, Speicher T and Werner S: Regulation of liver regeneration by growth factors and cytokines. EMBO Mol Med 2: 294-305, 2010.

21. Robbins DJ, Fei DL and Riobo NA: The Hedgehog signal transduction network. Sci Signal 5: re6, 2012.

22. Machado MV, Michelotti GA, Pereira Tde A, Boursier J, Kruger L, Swiderska-Syn M, Karaca G, Xie G, Guy CD, Bohinc B, et al: Reduced lipoapoptosis, hedgehog pathway activation and fibrosis in caspase-2 deficient mice with non-alcoholic steatohepatitis. Gut 64: 1148-1157, 2015.

23. Mitaka T, Ichinohe $\mathrm{N}$ and Kon J: Thy1-positive cell transplantation activates the growth of small hepatocyte-like progenitor cells in rat livers treated with retrorsine and PH. FASEB J 27: 257, 2013.

24. Best DH and Coleman WB: Bile duct destruction by 4 , 4'-diaminodiphenylmethane does not block the small hepatocyte-like progenitor cell response in retrorsine-exposed rats. Hepatology 46: 1611-1619, 2007.

25. Best DH and Coleman WB: Treatment with 2-AAF blocks the small hepatocyte-like progenitor cell response in retrorsine-exposed rats. J Hepatol 46: 1055-1063, 2007.

26. Agarwal JR, Wang Q, Tanno T, Rasheed Z, Merchant A, Ghosh N, Borrello I, Huff CA, Parhami F and Matsui W: Activation of liver $\mathrm{X}$ receptors inhibits hedgehog signaling, clonogenic growth and self-renewal in multiple myeloma. Mol Cancer Ther 13: 1873-1881, 2014. 